\title{
Estudio comparativo entre los planteos teóricos europeos e investigaciones empíricas mexicanas sobre las transformaciones sociales de las parejas y familias contemporáneas
}

\author{
Edgar Iván Zazueta Luzanilla*
}

\begin{abstract}
Resumen
Este artículo forma parte de las conclusiones de una investigación doctoral en la cual se propone discutir la relevancia de la teoría social sobre la modernidad y la transformación de la intimidad, a través del análisis de los planteos teóricos elaborados por autores europeos y en países desarrollados. Así mismo, su impacto en las parejas heterosexuales, a través de la revisión de investigaciones empíricas realizadas en México sobre las concepciones y relaciones de género, y los conflictos y transformaciones de las últimas cuatro décadas sobre las parejas y las familias heterosexuales. El contraste entre ambas producciones académicas se realiza a través de cinco dimensiones analíticas. Es un estudio cualitativo en el cual se realizaron 10 entrevistas a profundidad a parejas heterosexuales cohabitantes menores de 34 años de Hermosillo y Ciudad Obregón, Sonora y en configuración de pobreza.
\end{abstract}

Palabras clave: género, pareja, pobreza, modernidad.

\section{Summary}

This report is part of the conclusions of a doctoral research proposed to discuss the relevance of Social Theory on modernity and the transformation of intimacy through the analysis of theoretical approaches by european authors in developed countries and their impact on heterosexual couples through the review of empirical research carried out in Mexico about gender conceptions and relations, as well as, the conflicts and transfigurations of the last 4 decades on heterosexual couples and families. The contrast between both academic productions is done through five analytical dimensions. In a qualitative study, 10 in-depth interviews were conducted with heterosexual cohabitant couples under the age of 34 from Hermosillo and Ciudad Obregón living in poverty.

Keywords: gender, couples, poverty, modernity

\footnotetext{
* Licenciado en Psicología por el Instituto Tecnológico de Sonora, Maestro en Desarrollo Regional y Doctor en Ciencias por el Centro de Investigación en Alimentación y Desarrollo, A.C. Posdoctorado en la Maestría en Sustentabilidad de la Universidad de Sonora. zazuetaluzanilla@gmail.com
}

\section{Introducción}

Las discusiones referentes al tema de la intimidad y su transformación en el contexto de la modernidad se han hecho cada vez más presentes en la teoría social. Estas discusiones han involucrado a autores ampliamente conocidos en el mundo académico como Giddens (1992, 2003, 2005), Bauman (2000, 2001, 2003, 2005), Touraine (1995, 2001), Lipovetsky (1988), Castells (2000), Béjin (1987), Connell (2006), Alberoni (1979, 1986, 1992) y Beck (1986, 2001). La popularidad del tema de la modernidad y su impacto en la transformación de la intimidad tiene mucho que ver con el título del libro: La transformación de la intimidad, del teórico social británico Anthony Giddens (1992).

La modernidad se construye frente a un pasado que suele caracterizarse como "tradicional", "premoderno", "atrasado", u "obscuro". Claro está, en la medida en que el proyecto moderno es un proyecto que se renueva y se supera a sí mismo constantemente, pues ese es el rasgo distintivo de la modernidad. Los parámetros temporales y sociocontextuales de la díada "tradición-modernidad" no son fijos y estables. Por su parte, 
el término modernización ha sido usado preferentemente para referirse a los procesos económicos y sociales que se han construido con arreglo a esos valores y narrativas que van transformando el rostro de las sociedades (Núñez y Zazueta, 2012).

La revisión de la literatura ayudó a construir las dimensiones analíticas que se utilizan en este trabajo a partir de los planteos teóricos europeos y las investigaciones empíricas mexicanas sobre las transformaciones sociales de las parejas y familias contemporáneas. Estas dimensiones de estudio son: 1) amor y pareja, 2) familia, 3) roles de género, 4) trabajo y 5) sexualidad.

\section{Desarrollo y conclusiones}

Los elementos distintivos y contrastivos de los supuestos teóricos europeos y latinoamericanos de las transformaciones sociales modernas y sus repercusiones en la intimidad son, de acuerdo a las dimensiones analíticas estudiadas en este trabajo, las siguientes:

a) En la dimensión del amor y la pareja, los estudios europeos enfatizan el carácter no tradicional en la construcción y el desarrollo de las relaciones; mientras que los estudios latinoamericanos subrayan el peso de la tradición. Es por ello que no se puede hablar de que exista un amor líquido (Bauman, 2005) o un amor confluente (Giddens, 1992) en las parejas entrevistadas, sino que prevalece mayormente el amor romántico.

b) En la dimensión de la familia se ha afirmado, a través de los planteos europeos, el "carácter equitativo de las relaciones de género, lo que presupone la equidad y la democratización al interior de la vida familiar" (Castells, 2000). Los hallazgos de investigación de este trabajo se suman a lo que se ha documentado de los planteos latinoamericanos al afirmar que, pese a la creciente flexibilidad en los roles de género, aún persisten las relaciones asimétricas entre los miembros de la pareja y al interior de la vida familiar (García y Rojas, 2002). Por ejemplo, esto se puede ver en la sobrecarga de trabajo que se ha generado en algunas mujeres entrevistadas, al hacerse cargo ellas de las labores domésticas y productivas, sin que sus parejas varones se involucren al ámbito reproductivo de la misma forma que al ámbito público-productivo.

c) En la dimensión de los roles de género, los planteos teóricos europeos enfatizan el carácter democrático y equitativo de las relaciones familiares y con ello, un supuesto "debilitamiento de la autoridad ejercida por el varón al interior de la familia" (Castells, 2000).

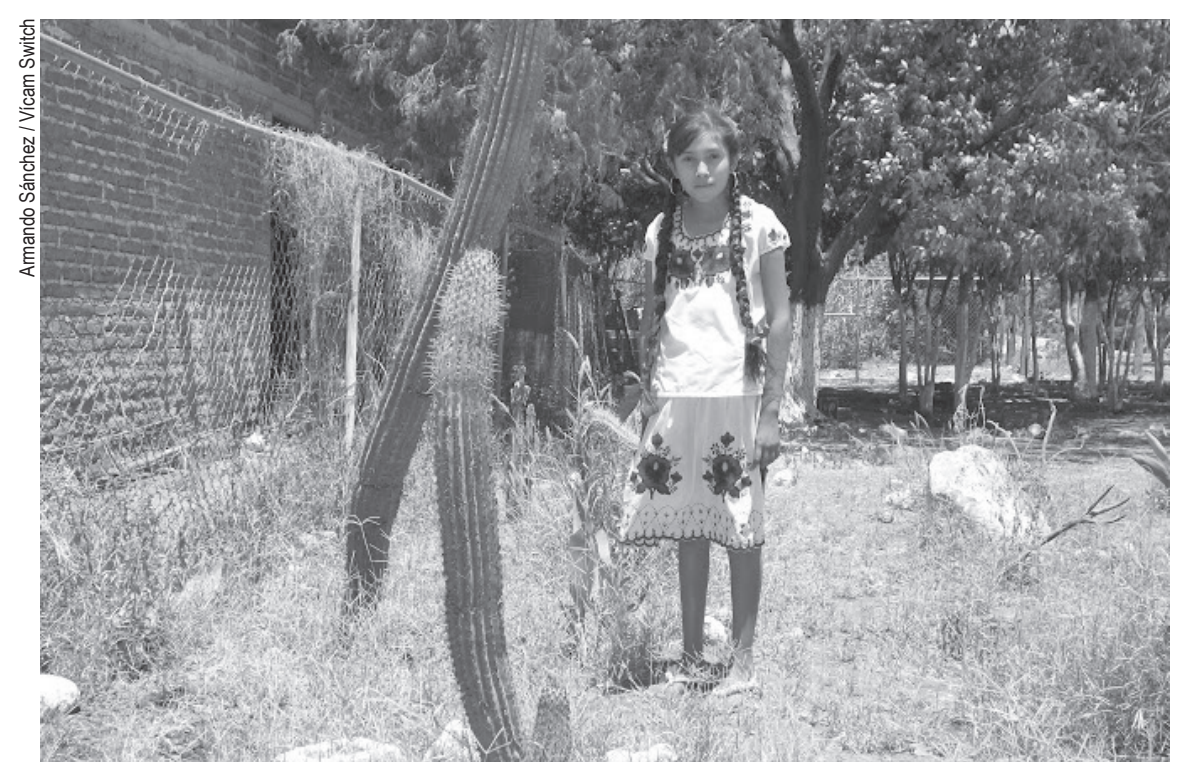

La oradora. Campeona de oratoria por el privilegio de ser bilingüe: español-lengua yaqui. (A. Valenzuela).
Los estudios latinoamericanos que se consideraron para este trabajo, incluida esta investigación, documentan las contradicciones en las relaciones de género, las resistencias al cambio de los varones y su escasa, aunque creciente, participación en roles de género no tradicionales en el espacio doméstico y la proliferación paulatina de otras formas de organización familiar. Por ejemplo, se observan tendencias que nos hablan de que hay un mayor involucramiento del varón en la esfera privada, en asuntos como la crianza de los hijos (menormente de las hijas) o la "ayuda" en la elaboración de los alimentos que se consumen en familia e individualmente.

d) En la dimensión del trabajo, se argumenta desde los planteamientos europeos una "flexibilización laboral que configura una nueva sociedad, la de los consumidores" (Bauman, 2000). Esto propicia nuevas reglas y esquemas de inserción y dinámica laboral que impactan en la vida íntima a través de la postergación o rechazo al matrimonio. En los planteamientos mexicanos se muestra el impacto desigual de la pobreza, tanto en hombres y mujeres (es por ello que se habla de feminización de la pobreza), en las dinámicas de pareja o en los patrones de unión o conyugalidad. Esto lleva a un casamiento o unión temprana de las parejas que desean hacer frente a la pobreza. Esto se considera un acto solidario.

e) En la dimensión de la sexualidad, se afirma desde los planteamientos europeos, una mayor importancia de la sexualidad en la pareja, lo cual coincide con los hallazgos de investigación de este trabajo. Sin embargo, en los estudios latinoamericanos como en este trabajo, también se puede observar la presencia contrastiva y contradictoria con valoraciones modernas de la sexualidad, según distintas categorías sociales tales como el género o la clase, entre otras. Lo anterior permite afirmar que no existe propiamente una sexualidad plástica (Giddens, 1992) en las parejas entrevistadas, sino un modelo híbrido que conjuga elementos tradicionales y modernos en los valores y ejercicio de la sexualidad. 
Se puede decir que las diferencias más notables de las transformaciones sociales dela modernidadyla intimidad de los planteos teóricos europeos y los estudios latinoamericanos son porque los planteos europeos poseen una mayor tendencia hacia una visión androcéntrica. Esto al ser elaborados fundamentalmente por varones y por no poseer en todos los casos una clara postura feminista. Los supuestos teóricos europeos provienen de estudios teóricos sin evidencia empírica y que generalizan el análisis al no especificar dimensiones geográficas o sociocontextuales en donde se reproduce un discurso unívoco de la modernidad.

Por su parte, los estudios mexicanos y latinoamericanos como los de Fuller (1997, 2001), Viveros (2006), Esteinou (2004 y 2008), Quilodrán(1996), López y Salles (2000), García y Rojas (2002), Parrini (2002), Arriagada (2002), Burín (1999 y 2007), Lagarde (1997), Ariza y Oliveira (2001), Jiménez (2003 y 2007), Núñez (2007), Figueroa, et al. (2006), Figueroa y Liendro (1994) y Ponce (2002) son elaborados principalmente por mujeres y desde una perspectiva claramente feminista. Estos resultados de investigación son producto de evidencias empíricas que se ajustan a contextos sociocontextuales que enfatizan los matices y complejidad del aspecto social que analizan.

Estos elementos distintivos y contrastivos entre los supuestos teóricos europeos y latinoamericanos sobre las transformaciones sociales modernas de la modernidad y la intimidad, permiten afirmar que dichos planteos teóricos de la modernidad y la intimidad no son aplicables para entender en toda su complejidad lo que sucede en México con las parejas y las familias. La utilización de los supuestos teóricos europeos debe tomarse solamente como referencia de lo que puede estar sucediendo con las parejas y familias en otros países y las posibles influencias asociadas a los cambios globales que la modernidad supone y trae consigo. Es necesario tener una postura crítica apoyada en evidencia empírica para el uso de dichos planteos.
Las transformaciones sociales modernas han impactado fundamentalmente a la familia y a la identidad social de las mujeres básicamente en dos aspectos: la reivindicación del placer y la satisfacción sexual, y su entrada al trabajo remunerado o productivo. Tales aspectos son los ejes que configuran la presencia de concepciones de género modernas en el vínculo de pareja. El que haya mayor prevalencia de concepciones de género modernas en esos dos aspectos, no significa que no los haya en otros, pero no son más significativos.

En esta investigación todas las personas entrevistadas (excepto una mujer) provienen de familias disfuncionales, es decir, familias que presentaron conflictos que se revelaron como significativos entre sus padres. Todas las personas provienen de familias de origen pobre o con carencias económicas. La mayoría de las parejas provienen y conforman familias nucleares (con su cercanía al amor romántico) y muchas personas manifestaron que, en su papel de padre o madre, querían "hacer lo que no hicieron con ellos". Esto indica que la familia de origen en las personas entrevistadas tiene una importancia central en la conformación de sus propias familias. Hacer lo contrario a lo que aprendieron y conocieron en sus familias o hacer lo mismo, forma parte de un proceso de imitación que se configura con las dimensiones estructurales de su historia personalsocial y con la configuración particular de pobreza.

La importancia de profundizar en la relación con su familia de origen de las personas entrevistadas ayuda a comprender las concepciones de género. Los valores, expectativas y significados que giran en torno a la vida en pareja se interiorizan con base en una construcción previa que se configura, fundamentalmente, en su relación con sus educadores a temprana edad, y que se actualiza por la influencia de agentes y experiencias cotidianas actuales.

Las concepciones de género de las personas entrevistadas tienden a un modelo de hibridación cultural, en donde prevalecen concepciones

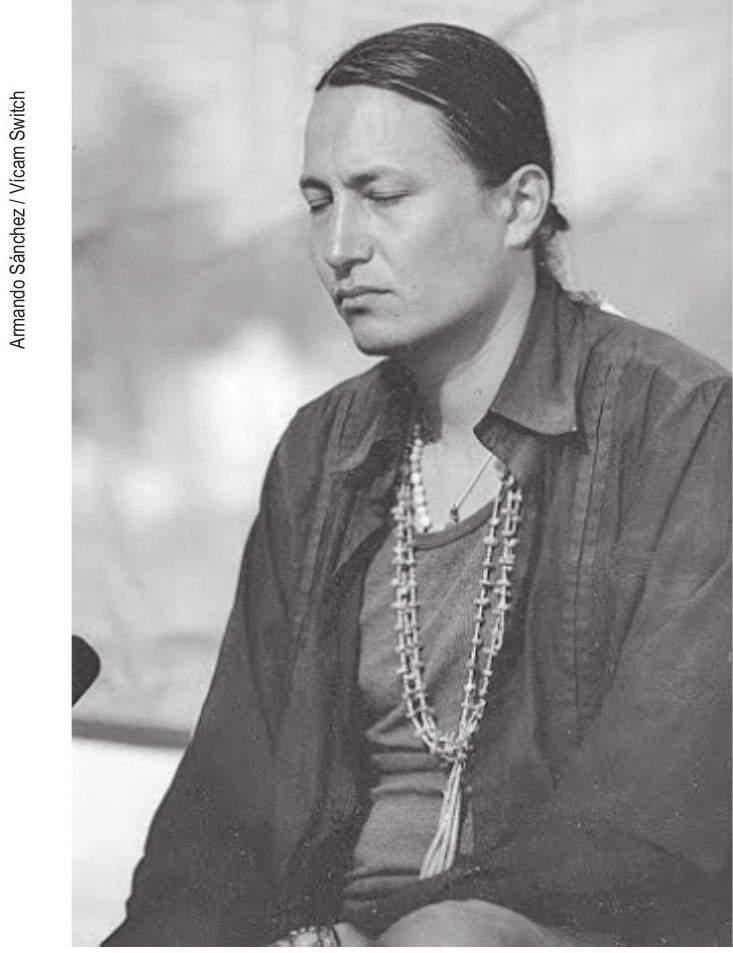

El Siux. Vino al encuentro continental de los pueblos indígenas y capturó las miradas de los ojos femeninos que habían visto hasta entonces solo ejemplares locales (A. Valenzuela).

de género tradicionales junto a otras modernas, asumiendo con esto que casi todas las parejas provienen de familias tradicionales. La hibridación trae consigo la idea de asimetrías al interior de la pareja, pero matizadas por pautas democráticas mayormente en el discurso y menormente en la práctica.

En esta investigación todas las parejas entrevistadas presentan concepciones de género tradicionales (fidelidad, división estereotipada de los roles de género y sexualidad, amor romántico y/o tipo del vínculo: matrimonio). La tradición conformada por las contradicciones en las concepciones de género y las resistencias al cambio, particularmente de los varones, configuran valores y conflictos particularmente en las áreas de la parentalidad y la articulación entre el trabajo remunerado y las labores domésticas.

Para conocer cómo participan las concepciones de género en los conflictos se construyeron tres tipologías de pareja denominadas como: atender y mantener, el matrimonio como empresa y la pareja solidaria. En 
cada una de estas tipologías se puede observar en mayor o menor medida cómo la tradición y la modernidad se presentan para enmarcar y calificar los cambios que se expresan al interior de la pareja y la familia. A continuación se describen los conflictos de cada tipología y su relación con las concepciones de género.

a) Tipología atender y mantener

Este tipo de relación de pareja parte fundamentalmente de una concepción tradicional estereotipada del género que está presente en menor medida en las otras dos tipologías. Su principal característica es la inconsciencia de suponer que hay espacios simbólicos y dimensiones de la vida en pareja que solo le corresponden cultural o naturalmente al hombre y la mujer. Esto lleva a una división sexual de género, que trae consigo que la función de mantener y cubrir necesidades al interior de la pareja y la familia debe ser por parte de los varones; y la de atender, dar soporte y comprensión a la pareja y a los miembros de la familia es por parte de las mujeres.

Los conflictos que viven las mujeres en este tipo de parejas tienen que ver con sus relaciones con la suegra (sobre todo cuando viven en un mismo espacio suegra y nuera), con las diferencias del estilo de crianza por cada miembro de la pareja y con el escaso involucramiento de los varones en las labores domésticas. Los conflictos que viven los varones tienen que ver con la pobreza, la falta de atenciones que sienten que reciben, las relaciones con la suegra y con la escasa participación de sus parejas en el ámbito productivo. Estos conflictos llevan a suponer que la mujer es la única responsable de las atenciones y cuidados que debe tener con el varón y la familia (y que no debe involucrarse al ámbito productivo); por su parte, el varón, no debe involucrarse en el ámbito doméstico. En ambos casos, eso está asociado a la rigidez de los roles de género.

b) Tipología el matrimonio como empresa

Este tipo de relación de pareja parte fundamentalmente del concepto de hibridación cultural, lo cual permite

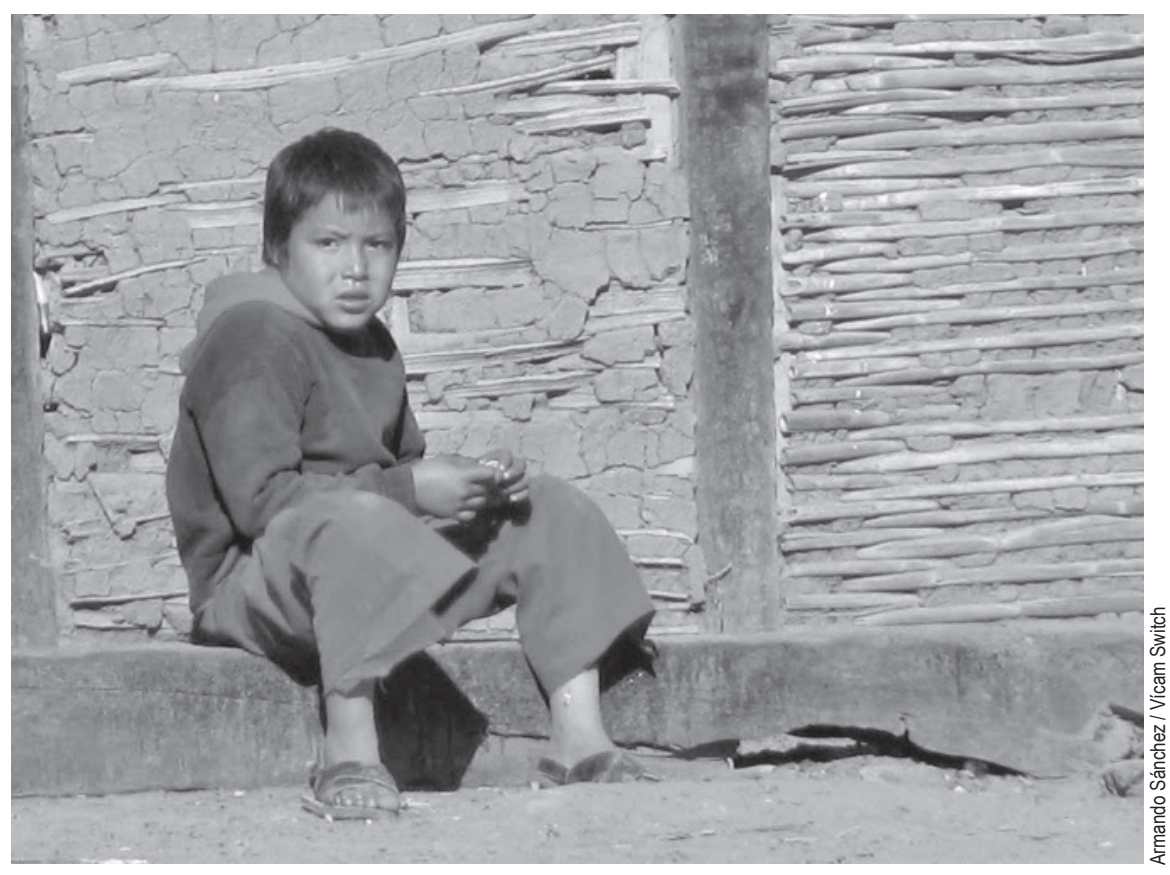

El Niño de Pótam. Infancia y pobreza: la desgarradora realidad en las comunidades yaquis (A. Valenzuela).

observar que en estas parejas existe una flexibilización de los roles de género en el discurso, pero no se aplica ni se visibiliza claramente en la práctica, sobre todo por parte los varones. La división sexual del trabajo sigue siendo tradicional y los hijos se constituyen como la fortaleza más importante de la unión en esta tipología.

Los conflictos que viven las mujeres tienen que ver con el hecho de que los varones no participan en el ámbito doméstico, con la pobreza y que existe una débil comunicación emocional con sus parejas. Los conflictos que viven los varones tienen que ver con sus limitaciones económicas, su escasa participación en el ámbito doméstico y que su pareja no tenga un trabajo remunerado. No consideran conflictivo que sus parejas les demanden mayor satisfacción sexual, sin embargo, es algo que señalan.

Estos conflictos llevan a suponer que existe un ideal de cooperación y equidad (concepción moderna de género) en la relación de pareja $\mathrm{y}$ al interior de la familia, pero no corresponde con las prácticas tradicionales de cada miembro de la pareja debido a las limitaciones económicas que condiciona el vínculo, lo cual genera una serie de contradicciones que son fuentes de conflicto.

\section{c) Tipología la pareja solidaria}

En esta última categoría, la hibridación cultural sigue jugando un papel importante en la manera de entender las trasgresiones y el rechazo al vínculo más tradicional de atender y mantener. Prevalece una alta valoración individual en confluencia de intereses personales por cada miembro de la pareja.

Los conflictos que viven las mujeres tienen que ver con su sexualidad (sus emociones, la presencia de celos e infidelidad) y con la personalidad del varón, lo cual está asociado al rechazo de un modelo machista de la masculinidad. Los conflictos que viven los varones tienen que ver con ellos mismos, y son por el mal uso que le dan al dinero, infidelidad, diferencias de carácter y por su poca participación en la crianza de los hijos y en las labores domésticas.

Estos conflictos llevan a suponer que existe una autocrítica y un reconocimiento personal de las fallas y limitaciones que presenta cada miembro de la pareja. Esto se debe quizás a la importancia que tiene la individualidad en este tipo de pareja, 
así como al deseo de romper con las concepciones de género tradicionales en las cuales se enmarca su historia de vida personal.

En todas las parejas se puede observar que las contradicciones entre las demandas de cambio modernas con las concepciones de género tradicionales y la organización del trabajo, mediante las interacciones entre las esferas pública y privada, es lo que genera a nivel íntimo, mayor conflicto en las personas entrevistadas.

Las parejas y las personas que presentan mayor presencia de concepciones de género modernas siguen actuando en condiciones de inequidad para las mujeres, y ellas, generalmente, no son conscientes de ello. Las que presentan concepciones de género tradicionales tienen mayor inequidad. Sin embargo, son las mujeres las que demandan cambios (participar en el trabajo remunerado, demandar satisfacción sexual, buscar que el hombre se involucre más en el ámbito doméstico) y los negocian en escenarios que construyen con sus parejas varones, pero dichos cambios (concepciones de género modernas) se regulan con sus concepciones de género tradicionales en torno a la maternidad y al amor. En cambio, ellos se resisten a participar en el ámbito doméstico de una manera amplia y constante. Algunos de ellos promueven que las mujeres participen en la esfera que tradicionalmente ellos han estado (el espacio público).

Mientras que las mujeres se han incorporado al ámbito público, la incorporación de los hombres al ámbito doméstico no se ha dado al mismo nivel. Esta situación genera sobrecarga de trabajo para las mujeres y situaciones de conflicto en la relación de pareja. Esta tensión conflictiva entre las esferas pública y privada conforma un elemento de tradición de las concepciones de género idealizadas.

En lo que respecta a la pobreza, esta se ha entendido como un proceso dinámico en donde asumirse como pobre o vivir situaciones de pobreza es un aspecto sensiblemente inaceptable de asumir. La pobreza es entendida en la mayoría de los casos como una situación extrema de vulnerabilidad.
Cuando se está en esa situación, la pobreza es entendida como algo muy subjetivo que alude a un carácter mental, emocional o incluso espiritual.

La pobreza no es la desventaja más grande en la armonía conyugal de las personas entrevistadas, incluso se ha visto que, en algunas parejas más que un elemento de disociación, fue de unión. La pobreza es la razón por la que el modelo de organización familiar caracterizado por la presencia del varón proveedor exclusivo ha estado menos presente. El salario insuficiente del varón es la razón por la cual ambos miembros de la pareja trabajan, cuando se da este caso.

Queda por saber si la visión tradicional está más presente en la pobreza. Al menos en este estudio, las parejas más pobres son más tradicionales. De igual manera falta analizar si el hecho de que ambos miembros de la pareja trabajen, genera mayor pobreza y los hace más vulnerables a lo que se llama, explotación de las clases trabajadoras y feminización de la pobreza.

Lo anteriormente expuesto contesta el cumplimiento de los objetivos de la presente investigación y se observa la aceptación de la hipótesis al aseverar lo siguiente:

1. Los cambios se regulan en un marco de concepciones de género tradicionales con relación al amor y la parentalidad.

2. La presencia de modelos híbridos en las concepciones de género de las relaciones de pareja.

3. Los cambios afectan de manera desigual a las mujeres que a los hombres.

No se ha podido analizar en este estudio si la presencia de estos cambios (con sus continuidades, resistencias, conflictos, tensiones y contradicciones) en las parejas estudiadas están presentes en parejas que no están en configuración de pobreza, si los modelos híbridos de las relaciones de pareja están regulados por otras variables además del género y la clase, como pueden ser la raza o la orientación sexual (por ejemplo, ¿las parejas en ambientes rurales tendrán las mismas características que las de ambientes urbanos? o ilas parejas homosexuales compartirán la misma tipología de conflictos que las heterosexuales?).

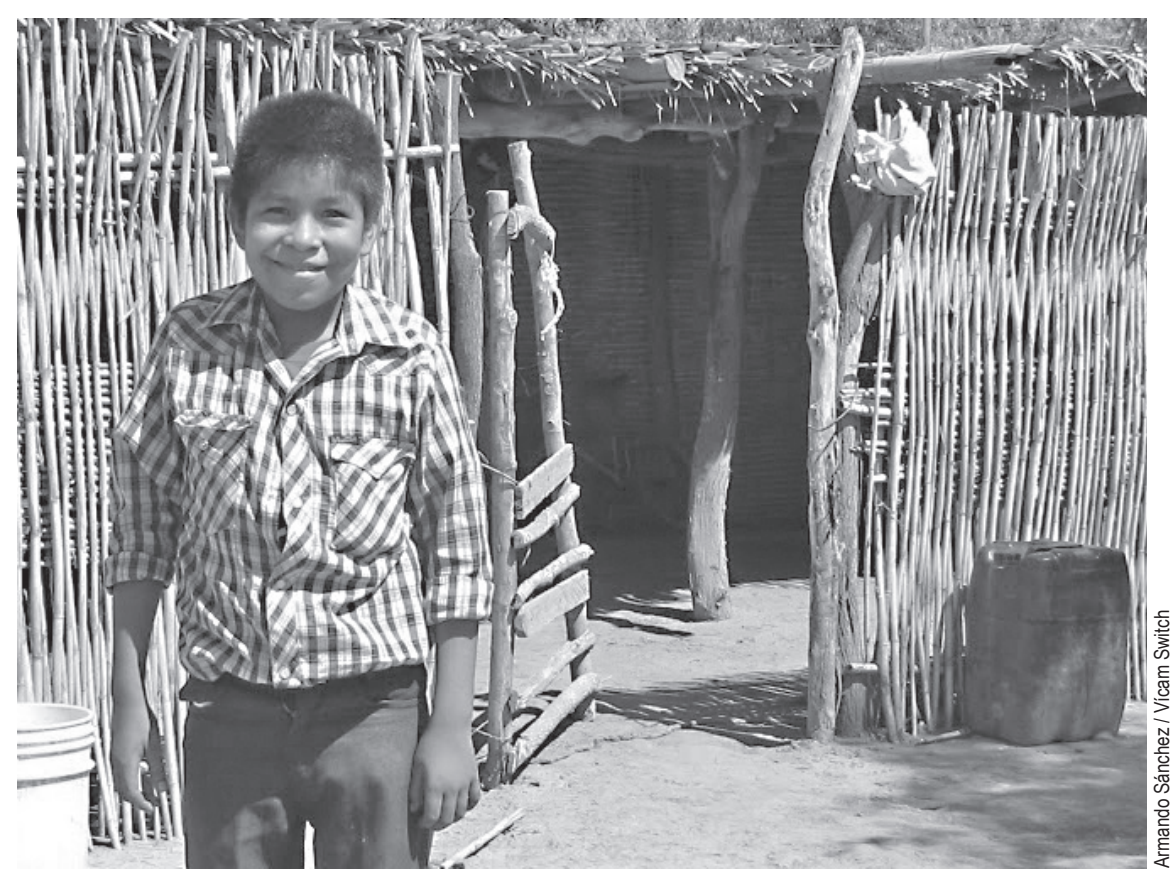

El niño cuentista. Este niño yaqui de las Guasimitas (un pequeño rancho entre Vícam y Pótam, yendo por el campo) escribe cuentos. Ya ganó un premio y el gobierno federal, generoso que es, le dio una laptop (A. Valenzuela). 
La comprensión de los resultados no es generalizable, pero es relevante ya que permite demostrar la utilidad de la teoría social contemporánea cuando se hace uso de categorías como las de clase, el género, la raza y la orientación sexual. Quizás nuevos trabajos empíricos puedan ofrecer un panorama más complejo y adecuado en torno a este punto. Se recomienda un estudio que haga un cruce de todas estas variables y tome en cuenta una mayor diversidad de parejas.

\section{Bibliografía}

Alberoni, Francesco. (1979). Enamoramiento y amor. España: Gedisa.

Alberoni, Francesco. (1986). El erotismo. España: Gedisa.

Alberoni, Francesco. (1992). El vuelo nupcial. España: Gedisa.

Ariza, Marina y Orlandina de Oliveira. (2001). Familias en transición y marcos conceptuales en redefinición. Papeles de población, (28), 9-39.

Arriagada, Irma. (2002). Cambios y desigualdad en las familias latinoamericanas. Revista de la CEPAL, (77).

Bauman, Zygmunt. (2000). Trabajo, consumismo y nuevos pobres. México: Gedisa.

Bauman, Zygmunt. (2001). La sociedad individualizada. España: Cátedra.

Bauman, Zygmunt. (2003). La globalización. México: Fondo de Cultura Económica.

Bauman, Zygmunt. (2005). Amor líquido. México: Fondo de Cultura Económica.

Beck, Ulrich. (1986). La sociedad del riesgo. Londres: Sage Publications.

Beck, Ulrich y Elisabeth BeckGernsheim. (2001). El normal caos del amor. Las nuevas formas de la relación amorosa. Barcelona: PaidósE1 Roure.

Béjin, Aries. (1987). El matrimonio extraconyugal de hoy. En: Aries Béjin, M. Foucault, et al. Sexualidades occidentales. México: Paidós.

Burín, Mabel. (1999). La familia: sexualidades permitidas y prohibidas. En: Mabel Burín e
Irene Meler (comps.). Género y familia. Poder, amor y sexualidad en la construcción de la subjetividad. (87-98 pp.). México: Paidos.

Burin, Mabel. (2007). Trabajo y parejas: impacto del desempleo y de la globalización en las relaciones entre los géneros. En: Ma. Lucero Jiménez Guzmán y Olivia Tena Guerrero (coords.). Reflexiones sobre masculinidades y empleo. (59-80 pp.). Morelos, México: Universidad Nacional Autónoma de México y Centro Regional de Investigaciones Multidisciplinarias (eds.).

Castells, Manuel. (2000). La era de la información, economía, sociedad y cultura, vol. 2. España: Editores siglo veintiuno.

Connell, R. W. (2006). Desarrollo, globalización y masculinidades. En: Gloria Careaga y Salvador Cruz Sierra (coords.). Debates sobre masculinidades. (185-209 pp.). México, DF: PUEG/UNAM.

Esteinou, Rosario. (2004). La parentalidad en la familia: cambios y continuidades. En: Marina Ariza y Orlandina de Oliveira (coords.). Imágenes de la familia en el cambio de siglo, escenarios en el cambio de siglo. México: Instituto de Investigaciones Sociales, UNAM.
Esteinou, Rosario. (2008). La familia nuclear en México: lecturas de su modernidad. Siglos XVI al XX. México: Miguel Ángel Porrúa.

Figueroa Perea, Juan Guillermo, Lucero Jiménez Guzmán y Olivia Tena, (2006). Ser padres, esposos e hijos: prácticas y valoraciones de varones mexicanos. México: El Colegio de México.

Figueroa Perea, Juan Guillermo y Eduardo Liendro. (1994). Algunos apuntes sobre la presencia del varón en la toma de decisiones reproductivas. Ponencia presentada en el seminario Hogares, Familias: desigualdad, conflicto, redes solidarias y parentales. Aguascalientes, México.

Fuller, Norma. (1997). Fronteras y retos. Varones de clase media del Perú. En: Teresa Valdés y José Olavarría (eds.). Masculinidad/es, poder y crisis. Chile: Ediciones de las Mujeres no. 24, ISIS/FLACSO.

Fuller, Norma. (2001). Masculinidades: cambios y permanencias. Perú: Universidad Católica del Perú.

García, Brígida y Olga Lorena Rojas. (2002). Cambios en la formación y disolución de las uniones en América Latina. Reporte técnico preparado para el Centro de Estudios Demográficos y de Desarrollo Urbano y El Colegio de México. 
Giddens, Anthony. (1992). La transformación de la intimidad. España: Cátedra.

Giddens, Anthony. (2003). Consecuencias de la modernidad. España: Alianza Editorial.

Giddens, Anthony. (2005). Un mundo desbocado. Los efectos de la globalización en nuestras vidas. España: Taurus.

Jiménez Guzmán, María Lucero. (2003). Dando voz a los varones. Sexualidad, reproducción y paternidad de algunos mexicanos. Morelos, México: UNAM/ Centro Regional de Investigaciones Multidisciplinarias.

Jiménez Guzmán, María Lucero. (2007a). Sexualidad, vida conyugal y relaciones de pareja. Experiencias de algunos varones de los sectores medio y alto de la Ciudad de México. En: Ana Amuchástegui, e Ivonne Szasz. (coords.). Sucede que me canso de ser hombre... Relatos y reflexiones sobre hombres y masculinidades en México. (185-237 pp.). México, DF: El Colegio de México.

Lagarde, Marcela. (1997). Género y feminismo. España: Horas y horas.

Lipovetsky, Gilles. (1988). La era del vacio. Ensayos sobre el individualismo contemporáneo. España: Anagrama.

López, María de la Paz y Vania Salles. (2000). Familias y hogares en transición. Los vaivenes de la conyugalidad: una interpretación desde la cultura. Reporte técnico preparado para UNIFEM y El Colegio de México.

Núñez, Noriega, Guillermo. (2007). Vínculo de pareja y hombría: atender y mantener en adultos mayores del río Sonora, México. En: Ana Amuchástegui e Ivonne Szasz (coords.). Sucede que me canso de ser hombre... Relatos y reflexiones sobre hombres y masculinidades en México. (141-183 pp.). México, DF: El Colegio de México.

Núñez Noriega, Guillermo y Edgar Ivan Zazueta Luzanilla. (2012). Modernidades e intimidad: aproximaciones conceptuales para el estudio de las transformaciones de las parejas heterosexuales en México. Revista Estudios Sociales, $X X$ (segundo número especial).
Parrini Roses, Rodrigo. (2002). Historia(s) de familia. Apuntes para una historiografía de la paternidad en Europa y la América Colonial. En: Juan Guillermo Figueroa Perea (coord.). Ética, religión y reproducción: apuntes para una discusión. (287- 304 pp.). México, DF: Católicas por el derecho a decidir, A.C.

Ponce Jiménez, Marta Patricia. (2002). Sueños de transgresión. Historias femeninas: trabajo, amor y placer en un rincón del agro veracruzano. México: Instituto Veracruzano de la Cultura.

Quilodrán, Julieta. (1996). E1 matrimonio y sus transformaciones. En: Ma. de la Paz López (comp.). Hogares, familias: desigualdad, conflicto, redes solidarias y parentales. México: Sociedad Mexicana de Demografía, SODEME.

Touraine, Alain. (1995). Crítica de la modernidad. México: Fondo de Cultura Económica.

Touraine, Alain. (2001). ¿Podremos vivir juntos? México: Fondo de Cultura Económica.

Viveros Vigoya, Mará. (2006). El machismo latinoamericano. Un persistente malentendido. En: Mará Viveros, Claudia Rivera y Manuel Rodríguez (comp.) De mujeres, hombres $y$ otras ficciones. Género y sexualidad en América Latina. Colombia: Tercer Mundo Editores del Grupo TM S.A.

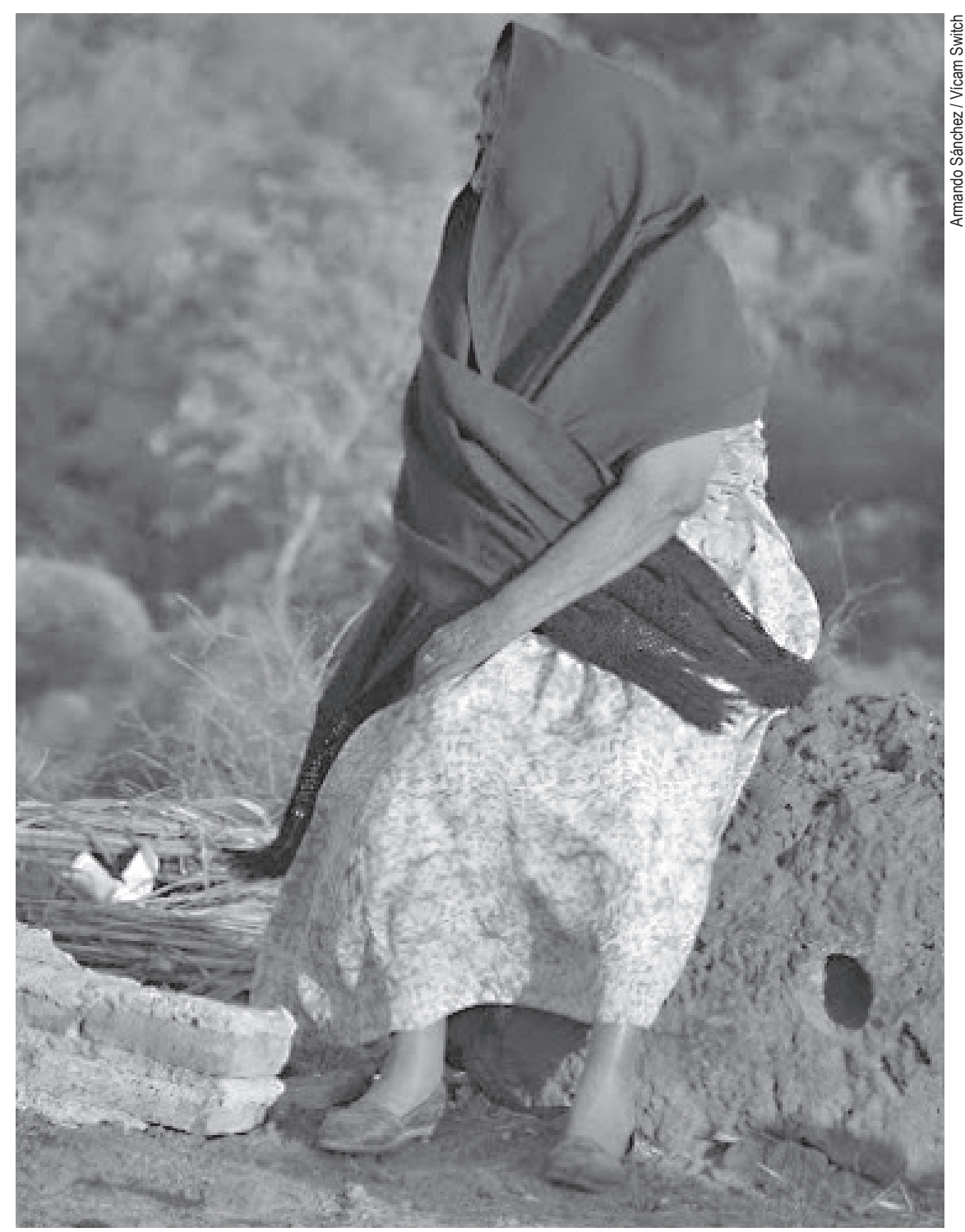

Mujer sentada en piedra. Tomándose un descanso antes de empezar la procesión de la Fiesta del Cerrito en Tórim (A. Valenzuela). 